\title{
Imported Lyme Disease
}

\author{
Satoshi Kutsuna ${ }^{1}$, Hiroki Kawabata ${ }^{2}$ and Norio Ohmagari ${ }^{1}$
}

Key words: Lyme disease, traveler, tickborne disease

(Intern Med 54: 691, 2015)

(DOI: 10.2169/internalmedicine.54.3700)

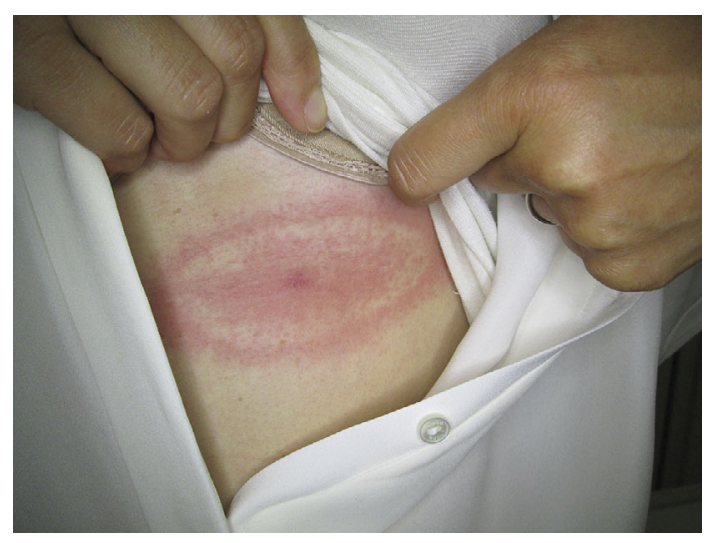

Picture.

by a tick approximately two weeks before admission. A physical examination revealed a bull's-eye rash in the epigastric region (Picture) with eschar tissue at the center of the rash. Other clinical examination findings were normal. Treatment with oral doxycycline was initiated, as we suspected a diagnosis of early localized Lyme disease. After completing the 14-day course of doxycycline (100 mg twice daily), the patient's rash disappeared. The serum antiBorrelia IgM titer was found to be positive in the recovery phase, thus confirming the diagnosis of Lyme disease.

Early localized Lyme disease usually occurs within one month after an Ixodes tick bite and is typically characterized by the presence of erythema migrans skin lesions (1).

The authors state that they have no Conflict of Interest (COI).

A previously healthy 39-year-old woman presented to our hospital with a rash. Three days prior to admission, she had returned to Japan after travelling to the United States for four weeks, including camping in the forest of Milwaukee, Wisconsin with her family. She reported having been bitten

\section{Reference}

1. Steere AC. Lyme disease. N Engl J Med 321: 586, 1989.

\footnotetext{
${ }^{1}$ Disease Control and Prevention Center, National Center for Global Health and Medicine, Japan and ${ }^{2}$ Department of Bacteriology, National Institute of Infectious Diseases, Japan

Received for publication July 18, 2014; Accepted for publication July 27, 2014

Correspondence to Dr. Satoshi Kutsuna, sonare.since1192@gmail.com

(C) 2015 The Japanese Society of Internal Medicine Journal Website: http://www.naika.or.jp/imonline/index.html
} 